\title{
PENGARUH PERCEIVED VALUE TERHADAP LOYALTY DAN PURCHASE INTENTION PADA RAGNAROK MOBILE GAME DI JAKARTA
}

\author{
Diana Chandra didjaja \\ Program Studi Magister Manajemen Universitas Tarumanagara \\ rambomeldina@gmail.com \\ Yanuar \\ Program Studi Magister Manajemen Universitas Tarumanagara
}

\begin{abstract}
Huge growth potential has been predicted for in-app purchases and the mobile game market but little is known about what motivates game players to make purchases in mobile game. This study aims to determine the main factors that can influence the purchase intention from players in Ragnarok mobile games. Based on previous research, this study revealed perceived value and loyalty of all players can attract purchase intention. This is a descriptive research by using questionaire which distributed to 120 respondents in Jakarta area. Data was collected by using non probability sampling method. SEM analysis were used for data analysis by using SmartPLS. From this study, it was found that variable perceived value and variable loyalty can influence purchase intention significantly. It was found that loyalty can be a mediator between perceived value and purchase intention.
\end{abstract}

Keywords : Purchase Intention, Perceived Value, Loyalty, Mobile Games

\begin{abstract}
Abstrak : Potensi pertumbuhan yang besar telah diprediksi untuk pembelian aplikasi dan pasar game mobile, tetapi sedikit yang diketahui tentang apa yang memotivasi para pemain game untuk melakukan pembelian dalam game mobile tersebut.Penelitian ini bertujuan untuk mengetahui faktor utama yang dapat mempengaruhi minat beli dari para pemain Ragnarok game mobile. Berdasarkan penelitian terdahulu, penelitian ini mengungkapkan perceived value dan loyalitas para pemain game dapat menarik minat beli konsumen. Jenis penelitian yang digunakan adalah penilitian deskriptif, dengan menggunakan sejumlah 120 kuesioner yang tersebar terhadap responden di Jakarta. Pengambilan sampel dilakukan dengan metode non probability sampling. Analisis data menggunakan analisis SEM yang diolah dengan program SmartPLS. Berdasarkan hasil penelitian didapatkan bahwa pengaruh variabel perceived value dan loyalitas berpengaruh secara signifikan terhadap purchase intention. Didapatkan juga bahwa loyalitas dapat menjadi mediator antara variabel perceived value dan purchase intention.
\end{abstract}

Kata Kunci : Perceived Value, Perceived Value, Loyalitas, Game Mobile

\section{Latar Belakang}

Dewasa ini tidak dapat dipungkiri lagi, bahwa teknologi kini sudah menjadi kebutuhan dalam kehidupan manusia. Salah satu perkembangan teknologi yang paling pesat adalah smartphone. Dengan adanya kemajuan internet, smartphone tidak hanya digunakan sebagai telepon tetapi dapat digunakan untuk berinteraksi satu dengan lainnya secara online melalui berbagai macam konten yang tersedia dalam smartphone tersebut. Salah satu konten online dari teknologi yang terkenal adalah game mobile dimana manusia tidak hanya bermain game saja, tetapi mereka dapat terkoneksi dengan manusia lainnya melalui internet dengan menggunakan smartphone (Choi dan Kim, 2004). Dengan keberadaan smartphone para pengguna kini dimudahkan dalam bermain game karena dapat digunakan untuk bermain game dimana saja dan kapan saja. 
Hampir semua game mobile dapat diunduh secara gratis melalui google playstore ataupun apple store, oleh karena itu untuk meningkatkan penggunaan dan mendorong pengguna untuk membayar, semakin banyak, perusahaan game mobile menyediakan layanan "freemium", yang tidak membebani biaya pemain untuk penggunaan dasar tetapi memerlukan pembayaran dalam uang nyata untuk fungsionalitas yang lebih menguntungkan atau menyediakan barang-barang virtual dalam game tersebut yang dapat dibeli dengan mengunakan mata uang riil ( Liu et al. 2015 ). Berdasarkan data yg didapat penjualan barangbarang virtual dalam game menjadi pendapatan utama bagi para developer game online. (Unity 2016 Mobile and VR Games Year in review).

Menurut laporan mengenai perkembangan pasar game mobile di dunia sepanjang tahun 2016 hasil kerja sama Unity Technologies dengan perusahaan analitik SuperData, didapatkan bahwa pemasukan industri game mobile global saat ini telah mencapai US\$40,6 miliar (sekitar Rp. 541 triliun) pada tahun 2016. Berdasarkan data mereka, saat ini Indonesia merupakan pasar yang memiliki potensial yang sangat besar dalam dunia game mobile. (Unity 2016 Mobile and VR Games Year in review)

Melihat besarnya potensi pengembangan bisnis game mobile yang sangat besar tentu membuat persaingan dalan bisnis game mobile juga semakin tinggi. Salah satu developer game mobile yang ikut bersaing dalam dunia persaingan game mobile adalah Gravity dan X.D Global yang membawa Ragnarok Online yang merupakan salah satu game online yang legendaris yang banyak diminati para gamer kembali ke Indonesia dalam versi mobile bernama Ragnarok M : Eternal Love atau yang lebih banyak dikenal dengan Ragnarok Online Mobile ( ROM ). Tetapi selain Gravity dan XD Global masih banyak developer yang ikut dalam persaingan bisnis game mobile, seperti Tencent, Moonton, GARENA dan masih banyak developer game lain nya. Oleh karena hal itu untuk dapat memenangkan persaingan dalam dunia bisnis game online, developer Ragnarok mobile game tentunya perlu mengetahui lebih jelas faktor-faktor apa sajakah yang menjadi pemicu intensi konsumen game mobile itu sendiri.

Karena pertumbuhan konsumen game mobile yang semakin meningkat setiap tahunnya, persaingan antara para developer game mobile yang semakin ketat dan adanya fakta bahwa pendapatan terbesar developer game mobile adalah dari penjualan produk virtual, maka penelitian ini bertujuan untuk menguji hubungan antara sejumlah variabel yang dapat membentuk purchase intention terhadap barang virtual dalam game mobile.

Berdasarkan latar belakang yang telah dikemukakan di atas, penulis tertarik untuk meneliti "Pengaruh Perceived Value Terhadap Loyalty dan Purchase Intention Pada Ragnarok Online Mobile Di Jakarta"

\section{Tujuan Penelitian}

Tujuan dilakukannya penelitian ini adalah sebagai berikut:

a. Bagaimanakah pengaruh perceived value terhadap purchase intention produk virtual Ragnarok Online Mobile?

b. Bagaimanakah pengaruh perceived value terhadap loyalty para pemain Ragnarok Online Mobile?

c. Bagaimanakah pengaruh loyalty terhadap purchase intention produk virtual Ragnarok Online Mobile?

\section{Tinjauan Pustaka}

\section{a. Perceived Value}

Perceived value pelanggan merupakan penilaian pelanggan yang dilakukan dengan cara membandingkan antara manfaat yang akan diterima dengan pengorbanan yang dikeluarkan untuk memperoleh sebuah produk / jasa. Menurut Sweeney dan Soutar (dalam Hsiao dan Chen, 2016) ada 4 dimensi nilai terdiri dari 5 aspek utama sebagai berikut : 


\section{Emotional Value (Playfulness)}

Playfulness merupakan bagian dari emotional value. Emotional value merupakan utility yang berasal dari perasaan atau keadaan efektif yang dihasilkan oleh mobile game (Lu dan Hsiao, 2010).

2. Performance value (Access flexibility)

Access flexibility merupakan bagian dari performance value. Performance value merupakan utility yang berasal dari perceived quality dan expected performance dari game mobile (Lu dan Hsiao, 2010).

\section{Social Value (Social Connectedness)}

Social Connectedness merupakan bagian dari social value. Social value merupakan utility yang berasal dari layanan game mobile untuk meningkatkan konsep diri sosial seseorang atau one's social self concept ( Lu dan Hsiao, 2010).

\section{Value for money (Good Price and Reward)}

Value for money merupakan utility yang berasal dari layanan game mobile karena adanya pengurangan biaya jangka pendek dan jangka panjang yang dirasakan (Lu dan Hsiao, 2010). Menurut Chu dan Lu (2007), good price adalah sejauh mana konsumen percaya bahwa layanan mobile game yang diterima senilai dengan biaya moneter. Dan menurut Hsiao dan Chen (2016) Reward adalah keuntungan yang diperoleh atau dialami saat bermain game mobile.

b. Customer Loyalty

Customer loyalty merupakan pelanggan yang melakukan pembelian ulang terhadap suatu barang atau jasa dari suatu perusahaan, menolak untuk membeli produk atau jasa serupa dari perusahaan lain dan merekomendasikannya kepada orang lain. Sedangkan dalam industri game mobile, mobile game loyalty adalah kesediaan pemain untuk memainkan kembali dan merekomendasikan game mobile tersebut kepada orang lain (Hsiao dan Chen, 2016).

c. Purchase Intention

Purchase intention adalah sikap konsumen secara sadar untuk membeli produk tertentu. menurut Hsu dan Lin (2014), Purchase intention didefinisikan sebagai kesediaan pengguna untuk membeli aplikasi berbayar (termasuk mobile game), membayar untuk menghilangkan iklan, menerapkan pembelian dalam aplikasi (barang-barang virtual) atau membayar untuk mendapatkan fungsi atau konten tambahan menyusul penerimaan keputusan awal.

d. Hubungan antar variabel

1. Pengaruh Perceived Value dengan Loyalty game mobile

Menurut Hsiao dan Chen (2016), Zhao dan Lu (2012), Perceived Value sangat mempengaruhi loyalty, ketika konsumen merasakan value yang didapatkan tinggi maka mereka akan terus bermain game online tersebut.

2. Pengaruh Perceived Value dengan Purchase Intention

Menurut Hsiao dan Chen (2016), Wei dan Lu (2014), Yi dan Jeon (2003), Yang dan Peterson (2004), Perceived Value mempengaruhi Purchase intention, ketika konsumen sudah merasakan kenikmatan dan kemudahan dalam bermain maka mereka akan terus bermain dan menimbulkan keinginan untuk membeli barang virtual dalam game tersebut untuk memberikan kemudahan yang lebih dalam bermain.

3. Pengaruh mobile game Loyalty dengan purchase intention

Menurut Hsiao dan Chen (2016), Loyalty dapat menjadi substantial value untuk konsumen maupun perusahaan. Ketika konsumen menjadi setia terhadap product/service, mereka juga dapat menghemat waktu yang diperhitungkan untuk mencari dan mengevaluasi alternatif pembayaran sehingga konsumen yang setia dapat memberikan revenue kepada perusahaan. Maka dari itu, pemain game mobile yang setia juga diharapkan memiliki niat lebih dalam melakukan purchase. 
Berdasarkan teori yang telah diuraikan di atas, maka akan diuji apakah perceived value dan loyalty berpengaruh terhadap purchase intention.Berikut adalah hipotesis dan kerangka pemikiran dari penelitian ini :

Dalam penelitian ini terdapat tiga hipotesis yang diuji, yaitu :

$\mathrm{H}_{1}$ : Apakah Playfullness berpengaruh signifikan terhadap purchase intention Ragnarok Online Mobile

$\mathrm{H}_{2}$ : Apakah Access flexibility berpengaruh signifikan terhadap purchase intention Ragnarok Online Mobile

$\mathrm{H}_{3}$ : Apakah Loyalty berpengaruh signifikan terhadap purchase intention Ragnarok Online Mobile

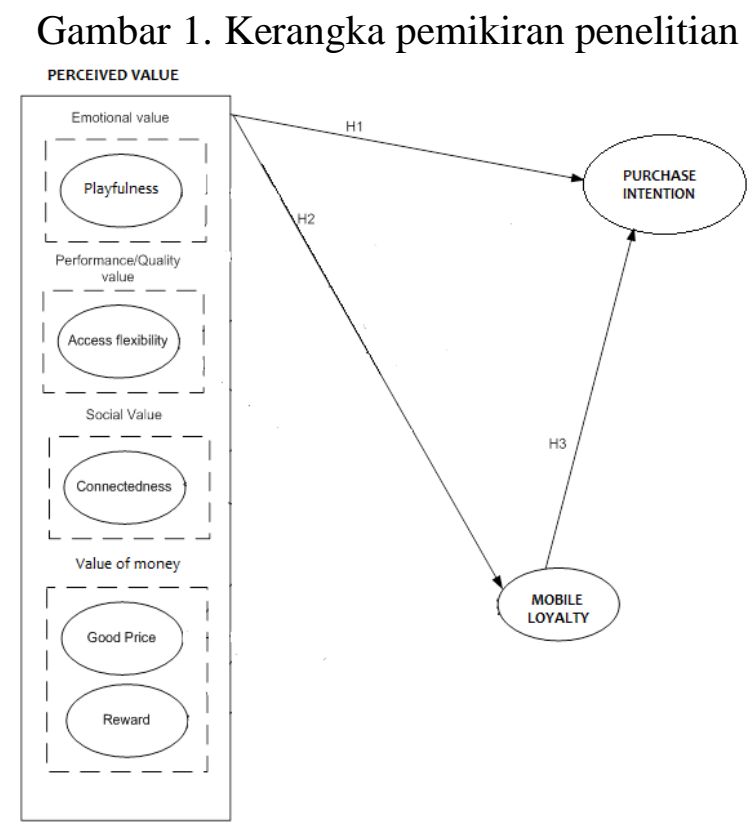

\section{Metodologi Penelitian}

Populasi dalam penelitian adalah para pemain game mobile Ragnarok di Jakarta. Ukuran sampel yang digunakan dalam penelitian ini adalah minimum sebanyak 120 orang. Dalam pengambilan sampel, metode yang digunakan adalah non probability sampling dengan teknik judgemental sampling. Skala pengukuran (kecuali profil responden) diukur dengan skala likert 1-5. Dalam tabel 1 menunjukkan instrumen masing-masing variabel beserta sumbernya.

Tabel 1. Variabel dan Pengukuran

\begin{tabular}{|l|c|c|}
\hline \multicolumn{1}{|c|}{ Variabel } & Item & Sumber \\
\hline Variabel independen: Perceived & 4 & Zhao dan Lu (2012) \\
value & 3 & Wei dan Lu (2014) \\
& 3 & Hsiao dan Chen (2016) \\
& 3 & Yi dan Jeon (2003) \\
\hline Variabel mediasi: Loyalty & 5 & Yang dan Peterson (2004) \\
\hline $\begin{array}{l}\text { Variabel dependen:Purchase } \\
\text { Intention }\end{array}$ & 3 & Hsiao (2013) \\
\hline Analisis SEM digunakan untuk mengetahui pengaruh masing-masing variabel
\end{tabular}

independen terhadap variabel dependen yang dilakukan dengan prosedur Bootstrapping.Sebelumnya, dilakukan terlebih dahulu uji validitas dan reliabilitas 


\section{Hasil Penelitian}

Tabel 2. Output Bootstapping

\begin{tabular}{|l|c|c|c|c|c|}
\hline & $\begin{array}{c}\text { Original } \\
\text { Sample } \\
(\mathrm{O})\end{array}$ & $\begin{array}{c}\text { Sample } \\
\text { Mean } \\
(\mathrm{M})\end{array}$ & $\begin{array}{c}\text { Standard } \\
\text { Deviation } \\
(\text { STDEV })\end{array}$ & $\begin{array}{c}\text { T Statistics } \\
\text { [O/STDEV] })\end{array}$ & P Values \\
\hline $\begin{array}{l}\text { Perceived Value } \rightarrow \\
\text { Loyalty }\end{array}$ & 0.704 & 0.704 & 0.068 & 10.308 & 0.000 \\
\hline $\begin{array}{l}\text { Perceived Value } \rightarrow \\
\text { Purchase Intetion }\end{array}$ & 0.529 & 0.514 & 0.127 & 4.183 & 0.000 \\
\hline $\begin{array}{l}\text { Loyalty } \rightarrow \text { Purchase } \\
\text { intention }\end{array}$ & 0.235 & 0.237 & 0.106 & 2.209 & 0.025 \\
\hline
\end{tabular}

Hasil hipotesis yang didapatkan dari uji Bootstrapping adalah sebagai berikut :

$\mathbf{H}_{1}$ : Perceived Value berpengaruh signifikan terhadap purchase intention Ragnarok mobile game

Berdasarkan hasil dari pengujian variabel perceived value terhadap purchase intention, maka dapat disimpulkan bahwa $\mathrm{H}_{1}$ diterima. Hal tersebut sesuai dengan penelitian yang telah dilakukan Hsiao dan Chen (2016), Zhao dan Lu (2012) jika para gamers mendapatkan lebih banyak kesenangan dan kemudahan (perceived value) dari game online tersebut akan meningkatkan keinginan untuk membeli barang virtual dari game online tersebut.

$\mathbf{H}_{2}$ : Perceived Value berpengaruh signifikan terhadap Loyalty Ragnarok mobile game Berdasarkan hasil dari pengujian variabel perceived values terhadap loyalty, maka dapat disimpulkan bahwa $\mathrm{H}_{2}$ diterima.Hal ini sesuai dengan penelitian Hsiao dan Chen (2016), Wei dan Lu (2014 ), Yi dan Jeon (2003), Yang dan Peterson (2004) yang menyatakan bahwa semakin pemain game merasakan kenyamanan dan kemudahan (perceived value) dalam bermain maka mereka akan terus bermain game online tersebut.

$\mathbf{H}_{3}$ : Loyalty berpengaruh signifikan terhadap purchase intention Ragnarok mobile game Berdasarkan hasil dari pengujian variabel loyalty terhadap purchase intention, dapat disimpulkan bahwa $\mathrm{H}_{3}$ diterima. Hal ini sesuai dengan penelitian Hsiao dan Chen (2016), Souza dan Freitas (2017) yang menyatakan semakin tinggi loyalitas para pemain terhadap game online tersebut maka keinginan untuk membeli barang virtual dari game tersebut akan semakin tinggi demi kenyamanan para pemain dalam bermain game tersebut.

\section{Kesimpulan}

Dari penelitian yang dilakukan dapat disimpulkan bahwa Perceived Value berpengaruh signifikan terhadap Loyalty dan Purchase Intention mobile game Ragnarok.

\section{Daftar Pustaka}

Choi, D., \& Kim, J. (2004). Why People Continue to Play Online Games: In Search of Critical Design Factors to Increase Customer Loyalty to Online Contents. CyberPsychology \& Behavior, 7(1), 11-24. https://doi.org/10.1089/109493104322820066

Chu, C., \& Lu, H. (2010). Factors influencing online music purchase intention in Taiwan An empirical study based on the. 17(2), 139-155. https://doi.org/10.1108/10662240710737004

Hsiao, K. L. (2013). Android smartphone adoption and intention to pay for mobile internet:Perspectives from software, hardware, design, and value. Library Hi Tech, 31(2), 216-235. https://doi.org/10.1108/07378831311329022

Hsiao, K. L., \& Chen, C. C. (2016). What drives in-app purchase intention for mobile games? An examination of perceived values and loyalty. Electronic Commerce Research and 
Applications, 16, 18-29. https://doi.org/10.1016/j.elerap.2016.01.001

Lu, H., \& Hsiao, K. (2010). Information \& Management The influence of extro / introversion on the intention to pay for social networking sites. Information \& Management, 47(3), 150-157. https://doi.org/10.1016/j.im.2010.01.003

Souza, Lucas Lopes Ferreira de and Freitas, Ana Augusta Ferreira de (2017). Consumer behavior of electronic games player: a study on the intentions to play and to pay. Revista de Administracao. 52, 419-430.

Wei, P. S., \& Lu, H. P. (2014). Why do people play mobile social games? An examination of network externalities and of uses and gratifications. Internet Research, 24(3), 313-331. https://doi.org/10.1108/IntR-04-2013-0082

Yang, Z., \& Peterson, R. T. (2004). Customer perceived value, satisfaction, and loyalty: The role of switching costs. Psychology and Marketing, 21(10), 799-822. https://doi.org/10.1002/mar.20030

Yi, Y. (2003). Journal of the Academy of Marketing Science Effects of Loyalty Programs on Value Perception, Program Loyalty, and Brand Loyalty. Journal of the Academy of Marketing Science, (1997). https://doi.org/10.1177/0092070303253082

Zhao, L., \& Lu, Y. (2012). Enhancing perceived interactivity through network externalities: An empirical study on micro-blogging service satisfaction and continuance intention. Decision Support Systems, 53(4), 825-834. 